\title{
9
}

Agregaduría Comercial de la Oficina Económica y Comercial de la Embajada de España en Qatar*

\section{LA ECONOMÍA DE QATAR: SITUACIÓN Y PERSPECTIVAS ANTE EL BLOQUEO}

El artículo pretende dar a conocer la estructura económica de Qatar, conocido por ser el país más rico del mundo, en términos per cápita, gracias a sus reservas de gas y petróleo. Se describen a continuación los antecedentes e implicaciones del conflicto diplomático con Arabia Saudí, Emiratos Árabes Unidos, Bahréin y Egipto. A su vez, se analiza el impacto del bloqueo sobre sus variables monetarias y financieras, así como sobre la economía real, incidiendo en las implicaciones comerciales y empresariales. Se explican también los retos a los que se enfrenta su economía, como el autoabastecimiento o la organización del Mundial de Fútbol FIFA 2022. Por último, se abordan la reacción de Qatar al bloqueo, las perspectivas económicas a largo plazo y las posibles estrategias de las partes implicadas para poder alcanzar una solución al conflicto actual.

Palabras claves: conflicto, mundial, gas, Golfo Pérsico, rial qatarí.

Clasificación JEL: D74, L71.

\section{Introducción}

Qatar alcanzó su independencia del protectorado británico en 1971, aunque es desde la toma del poder por el jeque Hamad en 1995 cuando el emirato ha buscado notoriedad tanto en Oriente Medio como en la esfera internacional. Una política exterior independiente, la recepción de grandes eventos internacionales, las inversiones exteriores en proyectos emblemáticos, el posicionamiento de Qatar Airways como aerolínea

\footnotetext{
* Este artículo ha sido elaborado por Miguel Ángel Fajardo, Agregado Comercial.

Versión de julio de 2018.

Mi agradecimiento al Excmo. Sr. Embajador de España en Qatar, D. Ignacio Escobar, por sus precisos comentarios y profundo conocimiento sobre el país.
}

de lujo que conecta Oriente con Occidente, la difusión de contenidos por su influyente cadena mediática Al Jazeera y la acogida de la sede para la Copa del Mundial de Fútbol en invierno de 2022 son las fórmulas utilizadas para situar a Doha en el mapa.

Sin embargo, desde junio de 2017, Qatar es también reconocida internacionalmente por el bloqueo impuesto por parte de Arabia Saudí (AS), Emiratos Árabes Unidos (EAU), Bahréin y Egipto, sumiendo al país en un contexto de incertidumbre sobre su futuro y sus relaciones con los países vecinos.

La pequeña península del Golfo Pérsico, del tamaño de la región de Murcia, es sin embargo el país más rico del mundo en términos de $\square$ 
Agregaduría Comercial de la Oficina Económica y Comercial de la Embajada de España en Qatar

renta per cápita, con casi 130.000 dólares al año (WEO, IMF, 2018). La monarquía musulmana, de corte wahabita, encabezada por el emir Tamin bin Hamad al Thani desde 2013, combina la tradición religiosa y social islamista con las excentricidades propias de un país rico que flota sobre la mayor reserva de gas natural del mundo.

Con una población de 2,6 millones de habitantes, de los cuales tan solo 313.000 son qataríes (PriyaDSouza Communications, 2017), la concentración de la riqueza es todavía mayor de lo que sugieren las cifras per cápita. La moderna capital Doha, fundada bajo el nombre de Albidda en 1825, representa la dicotomía en la que conviven deslumbrantes rascacielos, lujosos hoteles, grandes centros comerciales y museos de arquitectura vanguardista junto a una sociedad conservadora en valores y tradiciones islamistas, que en su mayoría se encuentra cómoda, bajo leyes vigentes propias de las monarquías absolutas de la Europa del xvill.

La ambición por posicionar a Qatar en el mundo ha levantado ampollas en los países vecinos, que ven con reticencias cualquier atisbo de cambio no autorizado en estas sociedades de fundamentos impertérritos. $Y$ es que cualquier destello intermitente en las blancas $y$ vastas llanuras del desierto molesta más a la córnea del beduino, despertando su curiosidad, sabedor de que en estos lares el oro es negro.

\section{Una economía basada en el gas}

Qatar es una economía emergente, de reciente desarrollo, especialmente a partir de los noventa, cuando decide explotar la reserva de gas de North Field que comparte con Irán, descubierta $1971^{1}$. Doha es la sede del Foro de Países Exportadores de Gas (GECF). Qatar también explota sus yacimientos petrolíferos y es miembro de la OPEP (Organización de Países Exportadores de Petróleo). Según la OPEP, Qatar produjo una media de 651.500 barriles de crudo al día y 182.800 millones de metros cúbicos de gas natural en 2016, que en términos de producción equivalente en barriles se traduce en una proporción porcentual de 65 a 35 a favor del gas (QNB Economics, 2017).

La situación geopolítica del emirato ha condicionado su forma de distribución y exportación del gas, invirtiendo para su transformación en Gas Natural Licuado (GNL). Por ello, es hoy en día el primer exportador de GNL del mundo, cuyos principales mercados de destino son Japón, Corea del Sur, China e India. Además es, después de Argelia, Nigeria y Noruega, el cuarto proveedor de gas natural de España (CORES, 2017). Qatar concentra casi el 80 por 100 de sus exportaciones en suministros energéticos y derivados por barco y mediante el gaseoducto Dolphin a Omán y EAU, con el que mantiene un acuerdo de suministro a largo plazo y la gestión compartida del mismo.

Esta fuente de riqueza natural comporta también sus riesgos, ya que casi la mitad del valor del PIB proviene del sector energético, lo que hace que la economía sea altamente dependiente de este recurso. Además, la ratio de reservas de gas en relación a los ritmos de producción actuales sitúa la esperanza de vida de sus reservas en 134,1 años (Oxford Business Group, Qatar 2017), por lo que el emirato se plantea muy seriamente la diversificación de la producción tal y como recoge el documento programático llamado «Visión 2030» (QNV, D

La producción comenzó en 1988, aunque la primera exportación a España tuvo lugar en 1997. 


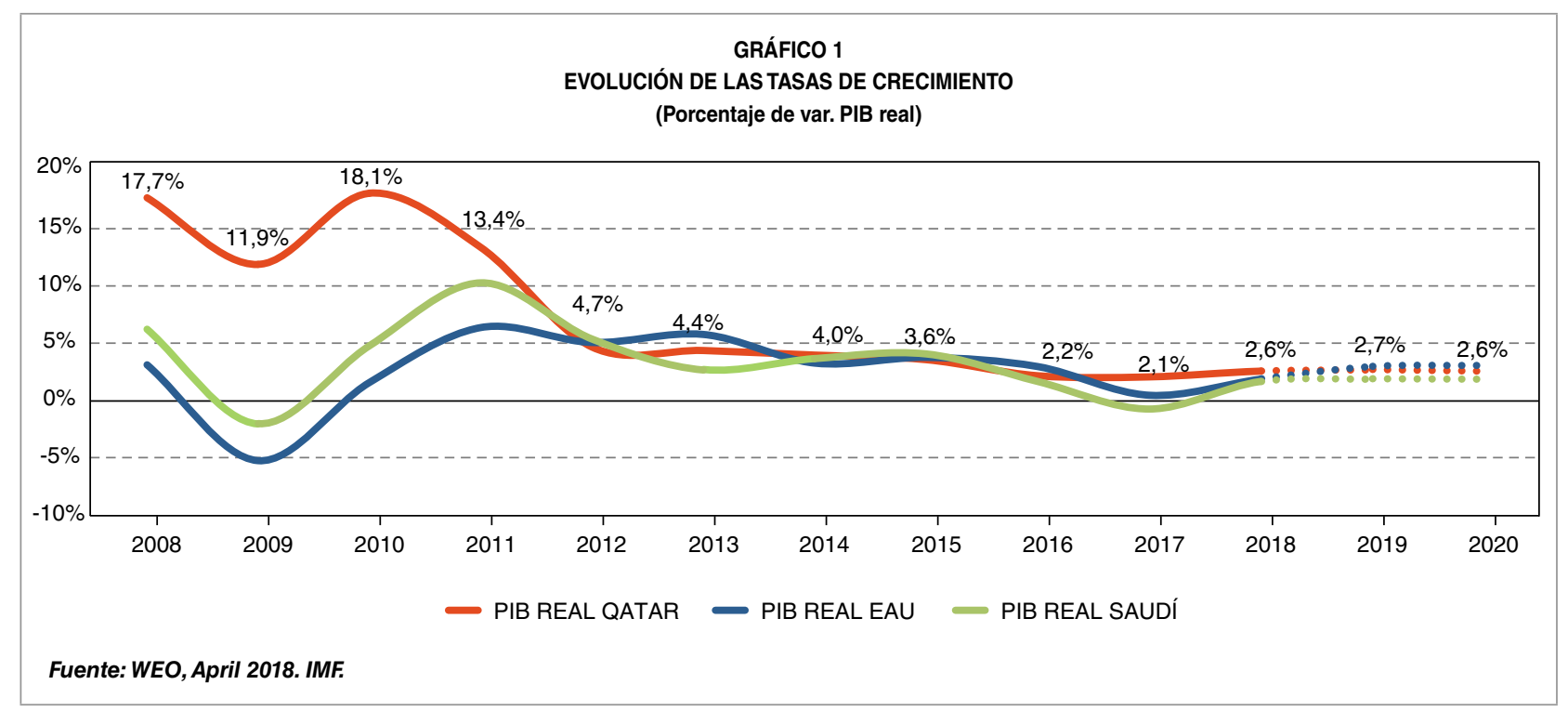

Qatar National Vision 2030) y sus acciones a medio plazo llamadas National Development Strategies (NDS, está operativa la 2. a NDS 2017-2022).

Fruto de estos recursos, la economía qatarí ha sido una de las más pujantes y dinámicas de la región del Golfo. La tasa de crecimiento del PIB real de Qatar registró cifras de dos dígitos desde inicios del siglo xxı hasta el año 2011 (Gráfico 1).

Sin embargo, la caída de los precios internacionales del petróleo y del gas marcó una desaceleración de su crecimiento desde 2012 hasta situarlo en la media de los países de Oriente Medio. Las menores tasas de crecimiento llegan a su punto de inflexión en 2017, cuando la OPEP acuerda la reducción de la producción de petróleo y consecuentemente los precios del crudo comienzan a subir. Qatar ve así vigorizar su crecimiento hasta el 2,6 por 100 previsto para 2018 (Art. IV FMI Qatar, abril de 2018).

En esta economía no es posible hablar de tasas de desempleo. Los qataríes ocupan puestos relacionados con las empresas públicas y ministerios (cuando no en empresas privadas por cuotas obligatorias, conocidas como «qatarización» del empleo) y el resto de la población no puede acceder al país sin un contrato y patrocinio previos. Una vez que el contrato vence, el trabajador deberá regresar a su lugar de origen siempre que no haya sido contratado por otro patrocinador en Qatar.

La normativa laboral, muy similar a la del resto de los países de la zona, es quizás la que más recelos despierta en occidente porque deja al trabajador al albur del humor del sponsor, que es como se conoce al empleador responsable del trabajador bajo el denominado sistema de Kafala. Así, según la Ley laboral $21 / 2015$ reguladora de la entrada y salida y residencia de expatriados, el sponsor tiene la facultad de denegar el permiso de salida NOC (Non Objection Certificate) del trabajador e incluso impedir la libertad contractual del mismo hasta que no hayan transcurridos dos años desde la firma del contrato.

Consciente de las críticas a su legislación laboral, Qatar ha alcanzado un acuerdo con las Naciones Unidas por el que la Organización Internacional del Trabajo ha abierto, en abril de 2018, una oficina en Doha para asesorar sobre las reformas laborales a acometer y con $D$ 
Agregaduría Comercial de la Oficina Económica y Comercial de la Embajada de España en Qatar

resultados a la vista, en especial respecto al NOC y resolución de disputas ${ }^{2}$.

Por otro lado, la tradición mercantilista de las antiguas zonas costeras del Golfo Pérsico confieren a Qatar o a EAU una predisposición al aperturismo, manteniendo lazos comerciales y de inversión más importantes con países occidentales y asiáticos que con sus socios de la unión aduanera del Consejo de Cooperación del Golfo (GCC por sus siglas en inglés) ${ }^{3}$.

Anodinamente, en 2016 la economía qatarí registró un déficit público, consecuencia de la merma en los ingresos debido a los bajos precios internacionales de los hidrocarburos y a una política de gasto en grandes infraestructuras. Así, pasó de un superávit del 1,3 por 100 en 2015 a un déficit del 9,3 por 100 del PIB en 2016 (IMF Art. IV Qatar, 2018).

Lejos de lo que pudiese haber sido un desprecio por las necesidades de financiación públicas, el Gobierno de Qatar impuso una política de racionalidad del gasto, mediante priorización de proyectos relacionados con el Mundial, fusiones de empresas públicas, despidos masivos de expatriados de «cuello blanco» de la Administración y reducción de salarios o complementos, que hicieron las delicias de las recomendaciones del FMI.

Desde el lado de los ingresos, subieron los precios de los combustibles y suministros (agua y luz) y las tasas de prácticamente todos los servicios públicos, desde correos a renovación de documentos. Se trataron de introducir, en mayo de 2017, los conocidos como Sin Taxes o impuestos sobre productos dañinos a la salud, aunque la aplicación del impuesto ha quedado

\footnotetext{
2 Entre otras, tiene previsto la introducción de un salario mínimo interprofesional, supresión del permiso de salida, que se espera de forma inminente, protección de los trabajadores y creación de un comité conjunto de trabajadores y empresarios para la resolución de disputas. En Qatar no existe la figura de los sindicatos.

3 Conforman el GCC: AS, EAU, Qatar, Omán, Kuwait y Bahréin.
}

suspendida sine die tras el bloqueo (se especula con su entrada en vigor en 2019). También se ha retrasado la implantación del IVA del 5 por 100, que desde 2018 se está aplicando en AS y EAU, prevista ahora para 2019.

De esta manera, en 2017 las necesidades de financiación del sector público se redujeron hasta el 6 por $100 \mathrm{y}$, aunque el FMI estima que en 2018 el déficit se contraiga hasta el 1,4 por 100, no debe descartarse la vuelta al superávit. Se espera que los ingresos públicos aumenten por encima de lo estimado en el escenario macroeconómico de los Presupuestos del Estado de 2018, ya que se fundamentan sobre un precio del Brent a 45 dólares/barril, claramente conservador dadas las cifras registradas de casi 75 dólares/barril en junio de 2018.

El anclaje del rial qatarí al dólar, con un tipo de cambio fijo de 3,64 riales/dólar desde 2001, es un instrumento muy potente que ha permitido a la economía no solo estabilizar las tasas de inflación, sino conferir un marco de confianza en el mercado para las inversiones. Por ello, el país se ha beneficiado de tasas de inflación relativamente reducidas del entorno del 3 por 100 , en un contexto de fuerte crecimiento económico para terminar en 2017 con una estabilidad de precios en términos de IPC del 0,4 por 100 (IMF Art. IV, abril de 2018).

Otro motor de la economía es el fondo soberano de inversión de Qatar, QIA (Qatar Investment Authority), creado en 2005 y considerado el 10. del mundo en valor de sus activos, 320.000 millones de dólares (SWFI, Sovereign Wealth Fund Institute, abril de 2018), que tiene por objetivo invertir bajo criterios de rentabilidad en proyectos fundamentalmente exteriores ${ }^{4}$. A través de su brazo inmobiliario $\square$

4 QIA tiene participaciones en empresas como Barclays, Volkswagen, Porsche, Total, EADS, GDF o France Telecom. 
(Qatar Diar), invierte desde 2005 en bienes inmuebles en distintos países con proyectos de renombre como el puerto deportivo de Tarragona o el Hotel Intercontinental de Madrid.

\section{El conflicto}

\subsection{Antecedentes}

Qatar ha jugado un papel activo coalineado con AS y EAU en numerosos conflictos regionales como el caso de Libia, Yemen, Siria o Palestina, tanto por interés económico como político.

Sin embargo, desde las revueltas de las primaveras árabes en 2011 no cerró filas con sus vecinos del Golfo en todos los lances. Apoyó, junto a Turquía y en contra de AS y EAU, a los Hermanos Musulmanes en Egipto, ocasionando un conflicto diplomático por el que los embajadores saudíes y emiratíes se retiraron de Doha, de febrero a octubre de 2014 , auspiciando entonces el actual desenlace de las relaciones entre vecinos.

Otro objeto de controversia ha sido el medio de comunicación qatarí Al Jazeera, más conocido en Occidente por ser la propietaria de la cadena deportiva Bein Sports y uno de los medios televisivos más influentes en el mundo árabe. Las monarquías absolutistas del Golfo veían a Al Jazeera con temor por la publicidad de las revueltas en el mundo musulmán y lo consideran un instrumento de injerencia en las cuestiones internas de otros países.

Las tensiones entre Qatar y sus vecinos del Golfo se volvieron a poner de manifiesto tras la visita, en mayo de 2017, del presidente Trump a Riad, siendo Qatar acusada de financiación del terrorismo islámico, acercamiento a Irán y apoyo a Hamas y Hezbollah.
Tras un ciberataque contra la agencia de noticias QNA que publicó un falso discurso del emir de Qatar, la escalada de acusaciones y desmentidos continuó. El 5 de junio de 2017 se produjo el anuncio del Reino de Bahréin, al que se unieron posteriormente AS, EAU, Yemen, Libia y Egipto, por el que se daban por terminadas las relaciones diplomáticas con Qatar y cerraban sus fronteras.

\subsection{La ruptura de relaciones diplomáticas $y$ el bloqueo}

La ruptura de relaciones diplomáticas implicaba, a diferencia de lo ocurrido en 2014, no solo el llamamiento de los embajadores a sus países de origen, sino el cierre de las embajadas, expulsión en 48 horas de los embajadores qataríes y la ruptura de la denominada coalición de Yemen, apartando a Qatar de la unidad que había cateterizado la colaboración militar de las partes en dicho conflicto.

Además, se informó a los ciudadanos qataríes residentes en AS, EAU, Bahréin y Egipto que disponían de dos semanas para volver a su país y la posterior prohibición de retorno. Esta medida fue un drama para familias compuestas por personas de origen en uno y otro bando ${ }^{5}$.

Los cuatro del bloqueo (como se les conoce en la prensa local) tienen prohibido el tráfico terrestre, aéreo y marítimo con Qatar en sus respectivas jurisdicciones. La frontera terrestre con AS al sur de Qatar permanece cerrada al tránsito, aislando a la península de $\triangle$

\footnotetext{
5 Parece que en un primer momento se detectaron casos aislados de rechazo de entrada a EAU a algunos europeos residentes en Qatar relacionados con la Administración Pública qatarí y otros casos posteriores de retenciones arbitrarias por horas a personas de diversas nacionalidades que residen en Qatar (incluso diplomáticos).
} 
su único acceso por tierra al GCC. Los puertos en AS, EAU y Bahréin permanecen cerrados a los pabellones de bandera qatarí y aquellos en tránsito hacia/desde Qatar. Etihad, Emirates, Fly Dubai y Air Arabia suspendieron los vuelos a Qatar y prohibieron a Qatar Airways utilizar su espacio aéreo. AS y Bahrein revocaron el mismo día 6 de junio la licencia de Qatar Airways para operar en sus territorios. Tan solo el canal de Suez no se vio afectado por el bloqueo.

AS también cerró inmediatamente la oficina de Al Jazeera en el país, prohibiendo cualquier retransmisión (aunque los sauditas no encontraron muchas dificultades para ver el Mundial de Rusia por vías alternativas).

Incluso, a pocas semanas del comienzo del Ramadán, AS impuso unas condiciones tan restrictivas para la peregrinación a la Meca de los musulmanes qataríes que relegaba a Qatar al mismo nivel de enemistad de Irán. Era tal el nivel de presión que nadie descartaba una posible sustitución del emir Tamin para facilitar la salida del conflicto. No tardaron en enarbolarse banderas púrpuras dentadas en blanco y fotografías con la cara del emir como muestras de apoyo a su líder y enaltecimiento del orgullo nacional.

Sin embargo, el aislamiento político de Qatar cambió radicalmente al recibir el apoyo explícito de Turquía. Estambul no solo condenó el bloqueo, sino que procedió inmediatamente a dar apoyo logístico a Qatar. Estableció líneas de suministro de bienes de primera necesidad y anunció el envío de un contingente de 600 soldados a su base militar de Qatar.

El apoyo turco no truncó la línea establecida por el cuarteto. El viernes 9 de junio divulgaron una lista de 59 personas y 12 entidades relacionadas con el emirato acusadas de terrorismo. Es más, el día 23 de junio presentaron las denominadas 13 exigencias $^{6}$ (posteriormente reducidas a seis «principios») para la resolución del conflicto. Qatar no asumió las demandas porque las consideraba un atentado a su soberanía nacional.

Por último, quedan por señalar dos cuestiones claves que han condicionado la evolución del conflicto. Por un lado, la base militar estadounidense de Al Udeid (que es la más grande del Golfo con más de 10.000 efectivos, instalada al sur de Qatar), que hace valer el interés estratégico militar americano en el área. Por otro lado, el triángulo promovido por el presidente Trump entre EEUU, Israel y AS, que ha resultado ser un frente común sólido contra Irán y Palestina.

\section{El impacto del bloqueo sobre la economía}

Bajo circunstancias económicas extraordinarias, los mecanismos de transmisión inmediatos de un shock son monetarios y financieros, dejándose sentir posteriormente en la economía real.

\subsection{Aspectos monetarios y financieros}

El jeque Abdulla bin Saoud al Thani, gobernador del Banco Central de Qatar (QCB en inglés), manejó las turbulencias financieras con gran $D$

\footnotetext{
6 Las condiciones impuestas fueron las siguientes: cierre de Al Jazeera, retirada de la base militar turca (en torno a cien militares desplazados en ese momento), romper vínculos con Irán, romper contacto con opositores a los regímenes de AS, EAU, Egipto y Bahréin, detener injerencias en asuntos domésticos de los países del Golfo, romper con Daesh, Al Qaida, Hizbolá, detener la financiación de entidades consideradas terroristas por USA, entregar a terroristas que están en su territorio y que son buscados por los cuatro países árabes en conflicto, alinearse con la política del GCC, no financiar medios de comunicación contrarios a los Gobiernos de los cuatro en conflicto, supervisión durante diez años de las medidas aplicadas por Qatar, compensación económica por la pérdida de vidas y por sus políticas, y aceptación en menos de diez días de las condiciones impuestas.
} 
éxito y en silencio. Si bien es cierto que aunque se trata de un país pequeño y rico, que contaba con reservas internacionales de más de 30.000 millones de dólares ${ }^{7}$, la estabilidad financiera no estaba garantizada. Así lo recogieron Fitch, S\&P y Moody's entre junio y agosto de 2017, rebajando los tres sus previsiones a negativas (aunque el 15 de julio de 2018, Moody's devuelve la previsión a estable) y los dos primeros el rating del soberano de AA a AA-.

La cotización de acciones en bolsa y el tipo de cambio son las principales variables que se resienten tras las turbulencias de la economía.

El índice del Qatar Stock Exchange (QSE o bolsa de Qatar) se desplomó un 22 por 100 entre mayo y noviembre (su nivel mínimo de 2017) como consecuencia del bloqueo. A partir de noviembre, el índice se estabilizó por encima de los 8.500 puntos, y a partir de abril de 2018 comenzó a fluctuar por encima del nivel de referencia de 9.000 puntos.

La autoridad monetaria actuó en cuatro frentes para ahuyentar los fantasmas financieros:

- Sostenimiento a cualquier precio del sistema de tipos de cambio fijos y evitar la depreciación de rial qatarí por motivos reputacionales.

- Inyección de liquidez en el mercado interbancario que ya venía registrando escasez de capitales durante 2016 y compensación de la fuga de depósitos extranjeros consecuencia del bloqueo.

- Salida a los mercados internacionales en búsqueda de financiación.

- Mantenimiento de ratios de solvencia y medidas macroprudenciales adecuadas según Basilea III. de QIA.
En relación al tipo de cambio, el QCB tuvo que afrontar las tensiones vividas contra el rial en diversos momentos. Tal y como se observa en el Gráfico 2, las tensiones en el mercado spot del rial se hicieron notar durante la semana siguiente al anuncio del bloqueo hasta alcanzar el tipo de cambio del 3,8 riales qataríes/ dólar. EI QCB actuó mediante compras de rial con cargo a reservas en los mercados offshore. Las tensiones siguieron durante los siguientes meses, hasta que en noviembre de 2017 se alcanzó la máxima depreciación del rial hasta 3,92 riales qataríes/dólar. Según apuntó el gobernador del QCB, este episodio obedeció a movimientos especulativos y fuga masiva de depósitos del cuarteto y terceros países, tras los cuales, los mercados descontaron las consecuencias del bloqueo y el tipo de cambio se estabilizó.

A la par que mantenía el cambio fijo con el dólar, el QCB tuvo que lidiar con dos fuerzas contrapuestas que condicionaban su base monetaria: el fin del quantitative easing americano, con las consecuentes subidas de tipo de interés de la Fed, y por otro lado inyectar la liquidez al mercado por la fuga de depósitos extranjeros. En relación a los tipos, el QCB subió en respuesta a la Fed, en marzo, junio y diciembre de 2017 los tipos de interés, hasta el 5 por 100 el del crédito (QNCBLR), hasta el 1,5 por 100 el de los depósitos (QCBDR) y hasta el 2,5 por 100 el repo (QCBRR) (QCB Quarterly Statistical Bulletin, abril de 2018). Para compensar la escasez de liquidez consecuencia de las subidas de tipos, el QCB inyectó a través de operaciones de mercado abierto - a corto plazo y estructurales- liquidez mediante una menor emisión neta de letras, reducción del coeficiente de reserva obligatorio en 25 puntos básicos hasta el 4,5 por 100 y especialmente con operaciones repo. 


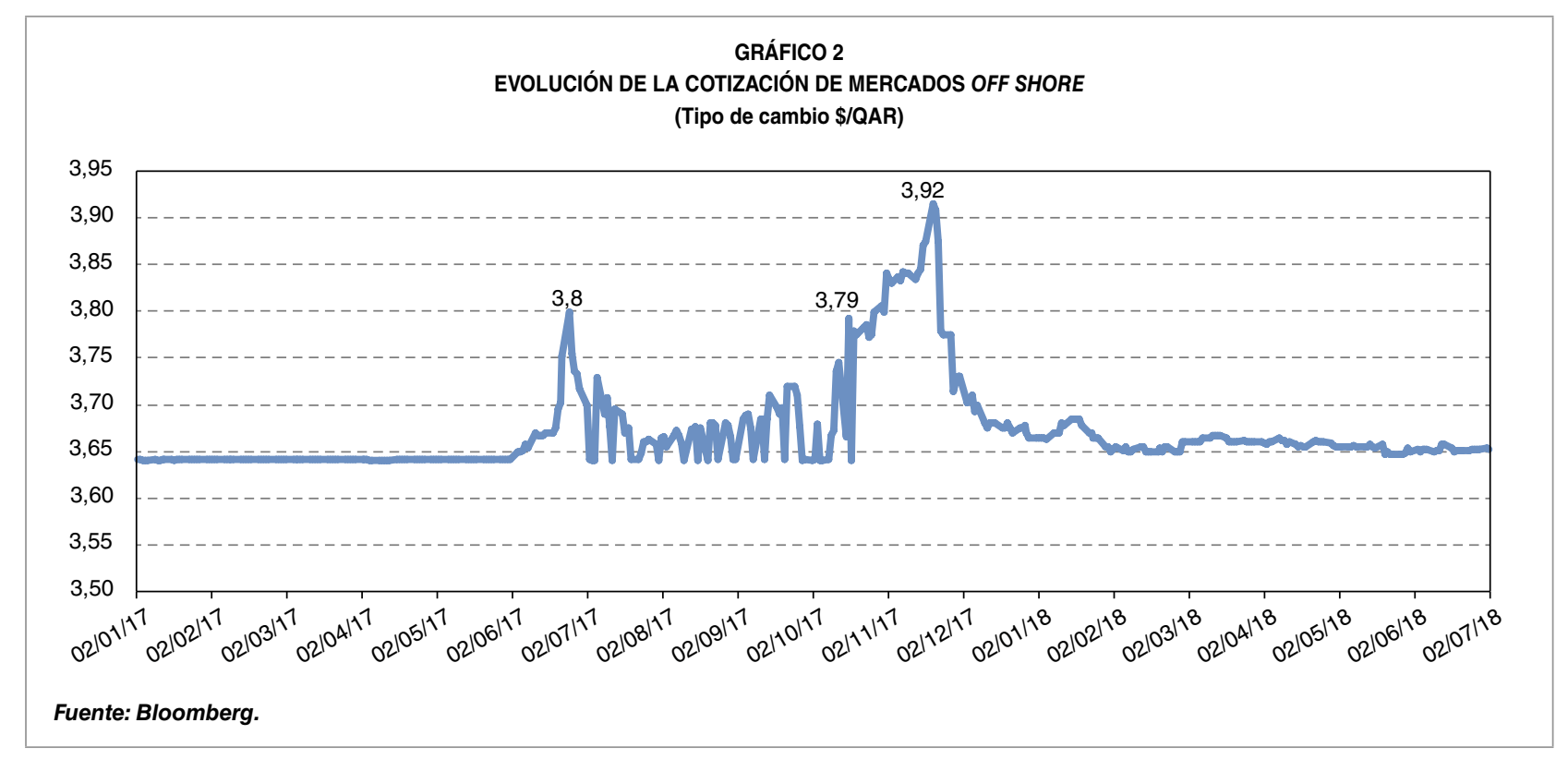

La fuga del 25 por 100 de depósitos de los no residentes, a finales de 2017 , se vio más que compensada con el aumento del 70 por 100 de los depósitos públicos (tanto del QCB como del QIA), modificando la estructura de los depósitos (Gráfico 3) y registrando un crecimiento del total de depósitos del 13,2 por 100. En términos absolutos, los depósitos de no residentes cayeron entre mayo y noviembre de 2017 de 50.000 millones de dólares a 37.000 millones de dólares. Para dar apoyo a la liquidez, QIA se ha visto obligada a deshacer algunas posiciones de sus activos en el exterior, aunque no le ha impedido realizar otras inversiones oportunistas con criterios de rentabilidad y también políticos.

En tercer lugar, Qatar supo financiarse con éxito en los mercados internacionales, con emisiones de bonos y sukuks ${ }^{8}$ por valor de 174.200 millones de dólares en 2017, un 4 por 100 más respecto al año anterior (9 ${ }^{\text {th }}$ Stability Report, QCB). El mayor reto se superó en abril de 2018,

8 Se conocen por sukuks a las emisiones de bonos islamistas, bajo premisas que no contemplan por ejemplo el pago de un tipo de interés. cuando el Gobierno lanzó con éxito una de las mayores operaciones de emisión de bonos del emirato por valor de 12.000 millones de dólares, cubriendo vencimientos de 5, 10 y 30 años con una gran aceptación de la demanda en su primera emisión tras el bloqueo.

En cuarto lugar, a pesar del entorno adverso, el QCB apostó por proyectar una imagen sólida de su sistema financiero, tomando medidas macroprudenciales y alcanzado las ratios de solvencia según Basilea III. El sistema bancario qatarí tan solo adolece de la alta interconexión bancaria a través del mercado interbancario, que lo hace vulnerable a problemas de liquidez, y una elevada concentración de la propiedad y control del sector privado no financiero, que se reparte entre pocas familias locales, con los consecuentes riesgos de crédito para el sistema financiero.

\subsection{Impacto sobre la economía real}

El anuncio del bloqueo sembró el pánico entre la población, que hizo acopio de alimentos $\triangleright$ 


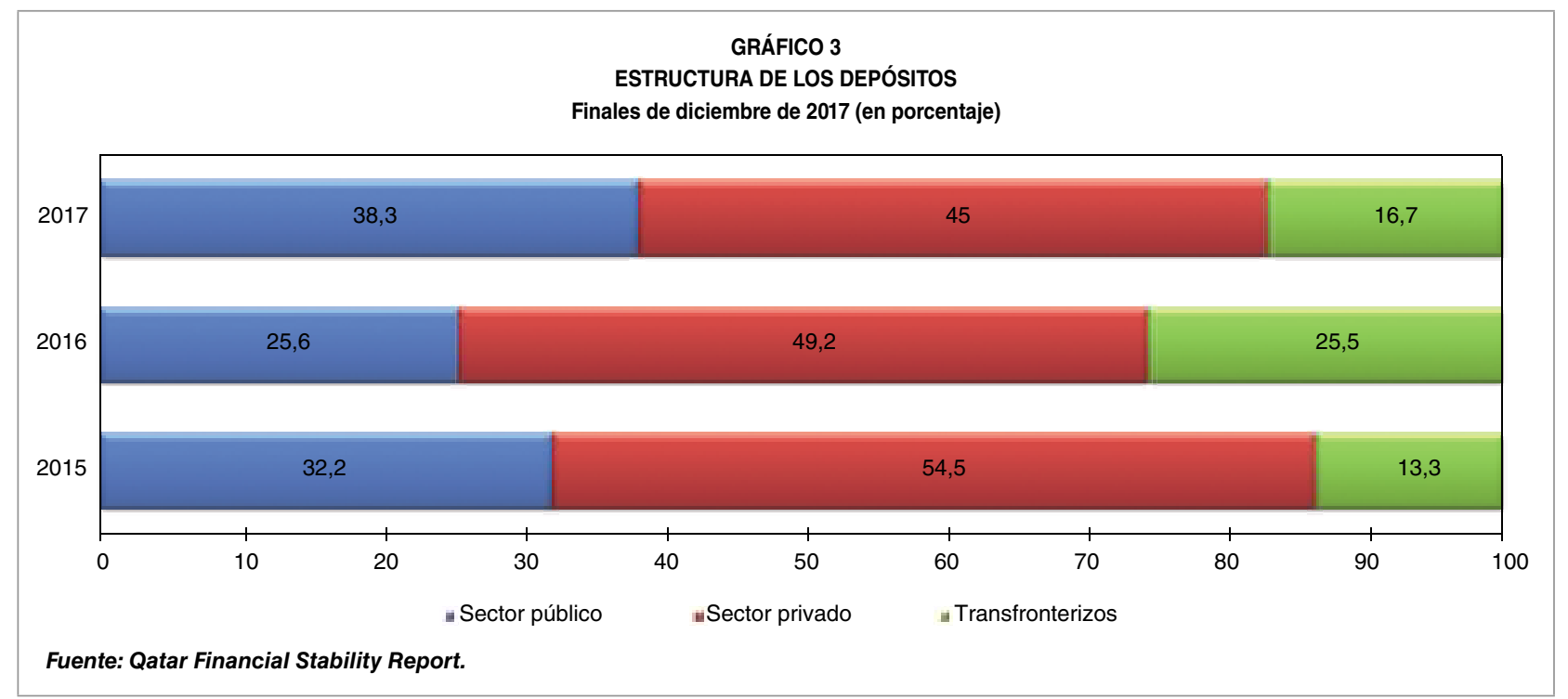

y de divisas, dejando imágenes de stands vacíos en supermercados y casas de cambio sin cash, como resultado de la histeria colectiva más que del bloqueo en sí.

Pero la dureza de las medidas impuestas contra Qatar intimidan más que infringen daño a sus relaciones comerciales debido a que sus principales socios no son sus vecinos, sino EEUU y sus compradores de gas, como Japón, Corea del Sur, India o China. Por eso, antes del bloqueo, EAU era solamente el $4 .{ }^{\circ}$ exportador en importancia para Qatar y AS, el 6.ำ representando respectivamente el 9 y el 4 por 100 del valor de las importaciones hacia Qatar. En términos de las exportaciones qataríes, tampoco son sus principales socios, representando EAU el 7 por 100 y AS el 1 por 100 del valor de destino de sus exportaciones (Comtrade, datos de 2016). El impacto del bloqueo se ha dejado notar en el conjunto del año 2017, reduciendo las importaciones procedentes de EAU y AS prácticamente a la mitad (de 3.500 millones de dólares a 1.900 millones de dólares y de 1.400 millones de dólares a 613 millones de dólares, respectivamente), mientras que las exportaciones a EAU no lo han hecho tanto (de 3.700 millones de dólares a 2.600 millones de dólares), pero sí las de AS (de 520 millones de dólares a 252 millones de dólares) (Boletín Trimestral, QCB, abril de 2018).

Aunque la intensidad de sus relaciones comerciales no sea elevada, sí que lo es en determinados productos que prácticamente se importaban en exclusividad desde AS y EAU, como acero e hierro, gabro, hormigones y asfaltos, y en productos de alimentación como yogures, leche y derivados, así como productos de origen aviar, y frutas y hortalizas.

En el caso de EAU, el mayor daño causado por el bloqueo es la pérdida del puerto de Jebel Ali, situado a $35 \mathrm{~km}$ al suroeste de Dubai, considerado el mayor hub o centro logístico de recepción y distribución de mercancías del Golfo Pérsico y almacén para Qatar, pues en dos días podía traer por vía terrestre cualquier mercancía, evitando tener que almacenar bienes en Doha. Por tanto, Qatar perdía sus puertas de acceso de suministro, tanto por la frontera terrestre por AS como por barco vía EAU. Es más, el 70 por 100 de los materiales de construcción usados en el $\triangleright$ 
Agregaduría Comercial de la Oficina Económica y Comercial de la Embajada de España en Qatar

país entraban por estas dos vías, poniendo en riesgo los proyectos de infraestructuras en marcha.

La pérdida del acceso a Jebel Ali llegaba además en el peor momento para Qatar, pues se encontraba en plena transición para sustituir el pequeño puerto de Doha por el Hamad Port, situado al sur del país, que contaría con tres terminales, un mejor acceso por carretera a la zona industrial, mayor profundidad para la entrada de grandes buques y más capacidad de almacenaje. Para Qatar, el acceso de mercancías se convertía en su principal fuente de preocupación por los cuellos de botella en almacenaje y transporte. A pesar del embargo, Hamad Port no pudo ser inaugurado hasta septiembre de 2017, estando solamente operativa una terminal y con problemas de estiba y cuellos de botella para el almacenaje y transporte. Se espera que cuando el Hamad Port esté totalmente operativo en 2020 tenga una capacidad de 7,5 millones de contenedores al año, contando con terminales separadas para cargas generales, cereales, vehículos y animales (Oxford Business Group, Qatar Report 2017).

Tras el desplome de un 40 por 100 de las importaciones de Qatar en el mes de junio de 2017, el Gobierno se apresuró a abrir nuevas rutas de suministro para garantizar el abastecimiento, conectando el Hamad Port con los puertos de Sohar y Salalah en Omán, con Esmirna en Turquía, Karachi en Paquistán, Shuwaikh en Kuwait, Mundra y Nahva Seva en India y Bushehr en Irán. De hecho, Qatar ha efectuado importantes inversiones en infraestructura portuaria en Omán y comprometido otras en Irán. La rápida reacción no solo evitó el colapso, sino que ha introducido la competencia de servicios portuarios en el Golfo frente al monopolio de Jebel Ali.
A pesar del uso de vías alternativas, se producían duplicidades en despachos aduaneros por vía marítima, primero en Jebel Ali y luego en Sohar - para poder tener acceso indirecto a Qatar- con el consecuente doble cargo del 5 por 100 sobre el valor de las mercancías. También aumentó el gasto en combustible por vía aérea al tener que bordear el espacio aéreo saudí.

Como resultado, en los meses posteriores al anuncio del bloqueo, aumentaron las tarifas de transporte desde el puerto Hamad en un 50 por 100 debido a las 36-72 horas de retención de los camiones en la terminal (Sesión Informativa del SBCQ, Logistics Challenges in Qatar, NGL, septiembre de 2017).

Por todo ello, las empresas de construcción instaladas en el emirato miraban a Ashghal (Ministerio de Fomento en Qatar) en busca de una actitud comprensiva y flexible con los plazos de ejecución y el reparto de los nuevos costes de producción. Sin embargo, Ashghal mantuvo la posición oficial de que el bloqueo impuesto a Qatar no sería considerado causa de fuerza mayor. Este jarro de agua fría para el sector privado, tan solo se alivió por la actitud flexible mostrada por la autoridad a la hora de reconocer y aprobar las nuevas listas de materiales y proveedores propuestas por los constructores.

Desde el punto de vista del derecho mercantil, el hecho de no reconocer la causa de fuerza mayor carga todo el ajuste de la crisis sobre el contratista, siempre que en su contrato no esté recogida detalladamente la circunstancia extraordinaria de un bloqueo comercial. Será la jurisprudencia la que vaya poniendo cotas a la responsabilidad mercantil de cada parte, pero hasta que haya sentencias en firme al respecto, la carga de la prueba recae sobre las empresas. 
Al contrario que con las mercancías, los suministros energéticos no se han visto alterados. El gaseoducto Dolphin sigue operativo, pues ni Abu Dhabi ni Doha pusieron sobre la mesa el suministro de gas a EAU por el interés de ambas partes. Hay que tener en cuenta que si Qatar hubiese cerrado el suministro de gas, buena parte de las centrales térmicas generadoras de la electricidad de EAU habrían parado.

\subsection{Qatar Airways, el gran perdedor del conflicto}

Si hay un claro perjudicado por el conflicto es, sin lugar a dudas, la aerolínea Qatar Airways (QA), con «enormes pérdidas», según declaró el propio director ejecutivo, Akbar Al-Baker, en marzo de 2018 ante el Parlamento Europeo. Fitch ya había estimado, en su actualización del rating de Qatar en agosto de 2017, que las pérdidas previstas eran del 10 por 100 en términos de pasajeros en los primeros meses de bloqueo.

QA actualmente vuela a más de 150 destinos y opera con una de las flotas más jóvenes del mundo, con Boeing 787 y Airbus 380 y 350 . A los 191 aviones disponibles en 2016 se le deben sumar los 300 que están bajo pedido, recibiendo 23 en 2017, como resultado de la apertura de quince nuevos destinos. Para poder absorber el número esperado de viajeros para el Mundial 2022, el moderno Aeropuerto Internacional de Hamad (HIA por sus siglas en inglés) se encuentra en fase de expansión. Se espera que aumente su capacidad de los 30 millones de pasajeros actuales a los 53 millones en 2021 (MEED, 2018).

El conflicto ha presionado al alza los costes operacionales de la aerolínea, que además ha absorbido otras en el exterior (la última adquisición fue Meridiana, la antigua Air Italia) para tener acceso a otros mercados sin la marca bloqueada de $\mathrm{QA}$.

Realmente, la clave que ha mitigado el efecto del bloqueo sobre la aerolínea, al menos en los primeros momentos, ha sido la apertura del espacio aéreo iraní a Qatar Airways, tanto para pasajeros como para carga, permitiendo que sobrevolase la frontera de Irak e Irán hacia o desde Europa.

\subsection{La caída de viajeros por el bloqueo golpea también el turismo}

En junio de 2017, el número de turistas cayó un 44,6 por 100 (Oxford Business Group, Qatar 2017). Según el Qatar Tourism Authority (QTA o Ministerio de Turismo), los visitantes pasaron de 2,94 millones en 2016 a 2,26 millones en 2017 (QTA, Annual Tourist Performance Report, 2017). Como consecuencia, la ocupación hotelera y de apartamentos cayó en 2017 hasta el 58 por 100, un 6 por 100 menos que el año anterior. La base del turismo qatarí eran las pernoctaciones de fin de semana de saudíes, que tras el bloqueo dejaron de viajar, presionando las tarifas a la baja por el exceso de capacidad en todos los segmentos hoteleros.

En todo caso, según recoge la Estrategia de Turismo de Qatar 2017-2023, se prevé que los visitantes anuales alcancen, para final de ese periodo, la cifra de 5,6 millones bajo una estrategia de promoción enfocada en cuatro áreas: patrimonio y cultura, deportes y ocio, turismo urbano y familiar, y, finalmente, de negocios. Para ello, Qatar ha abierto varias oficinas de turismo en diversos países objetivos, facilitado la exención de visados a la entrada desde agosto de 2017 para un conjunto de $80 \triangleright$ 
Agregaduría Comercial de la Oficina Económica y Comercial de la Embajada de España en Qatar

países $^{9}$ y apostado por un turismo marítimo, ampliando la profundidad del puerto de Doha para permitir la entrada de grandes cruceros. Qatar espera recibir 500.000 turistas en 2026 por este medio de transporte. Dentro de las labores de promoción turística, se recibió con éxito la iniciativa +Qatar, por la que los viajeros en tránsito podrían disfrutar de una noche gratis en hoteles de 5 y 4 estrellas en Doha, lo que ha aumentado este tipo de estancias en un 40 por 100 en el primer mes de aplicación y en un 26 por 100 en todo el año 2017 (QTA, Annual Tourist Performance Report, 2017).

\section{Retos para Qatar tras el bloqueo}

\subsection{Una economía orientada al Mundial de Fútbol}

Con el hito del Mundial en mente, Qatar debe acometer una inversión prevista en infraestructuras de más de 200.000 millones de dólares entre 2010-2022, posicionando al sector de la construcción como el más importante de la producción no energética, representando el 12,5 por 100 del PIB y un crecimiento del 15 por 100 en 2017 (QCB, Quarterly Statistical Bulletins, 2018). A pesar de los recortes del 40 por 100 en el presupuesto del Mundial reconocidos por el secretario general del Supreme Committee for Delivery and Legacy (SCDL, el comité encargado de la gestión del Mundial), Hassan Al Thawadi, en abril de 2017, la copa del mundo marca las prioridades de gasto público.

Ello implica el desarrollo de una macrociudad (Lusail City) situada al norte de Doha y

9 India, Turquía, la mayor parte de Europa, China, EEUU, Canadá, Sudáfrica e Indonesia, incorporando más tarde a Marruecos y Líbano entre otros. desarrollada por Qatar Diar con una inversión de 45.000 millones de dólares, que cuenta con capacidad prevista de acogida de 450.000 personas, que además será la sede del estadio de apertura y cierre del Mundial (con capacidad para 80.000 espectadores). Los ocho estadios del Mundial ya han sido adjudicados y se encuentran en fase de desarrollo y ampliación de los ya existentes. El sector hotelero también está viendo aumentar su capacidad, con la premisa de alcanzar más de 60.000 habitaciones partiendo de las 25.167 que se estima existen en la actualidad (QTA, Annual Tourist Performance Report, 2017).

Qatar Rail dirige el proyecto de metro, el tren ligero de Lusail y la red de larga distancia (hasta ahora paralizada) y espera ver terminar, en una primera fase, las tres líneas de metro en 2019, y una cuarta línea y extensiones de las tres anteriores en una segunda fase para 2026. Las infraestructuras de carreteras siguen siendo prioritarias bajo el Expressway Programme de Ashghal, con 35 carreteras en desarrollo y grandes proyectos en marcha, como la Autopista Orbital, conexión del área industrial con puerto y aeropuerto, así como la construcción de la carretera de Al Bustan y la actualización de las de Al Rayyan, Dukhan y Lusail.

\subsection{La gran apuesta por el autoabastecimiento}

La dependencia de Qatar de las importaciones ha quedado de manifiesto tras el bloqueo, poniendo en evidencia no solo la necesidad de diversificar su producción, concentrada en los hidrocarburos, sino en el desarrollo de las manufacturas y agricultura locales.

Para ello, el Gobierno ha aprobado un programa para facilitar las inversiones y buscar $\triangleright$ 
el autoabastecimiento. En primer lugar, flexibilizando la Ley 13/2000 que regula las inversiones extranjeras en Qatar, permitiendo a las empresas constituirse con el 100 por 100 del capital social extranjero en la mayoría de sectores (antes el límite era del 49 por 100) e invertir en participaciones de hasta el 49 por 100 de empresas cotizadas en bolsa, sujetas a aprobación del Consejo de Ministros.

En segundo lugar, en julio de 2017 se puso en marcha la incitativa fast tracking para facilitar la implantación de empresas que quieran producir localmente bajo el «Made in Qatar». El proyecto ofrecía 250 posibilidades de inversión para la industria con incentivos en los sectores agroalimentario, del metal, de plásticos y del papel.

Completan las medidas para atraer la inversión extranjera el apoyo financiero a la pyme y a sectores básicos como el agroalimentario, las piscifactorías o la ganadería que otorga el Qatar Development Bank en condiciones más favorables que las de mercado.

El objetivo de autoabastecimiento también se traslada al ámbito energético del emirato. Qatar Petroleum (empresa pública que explota los recursos energéticos locales) ha apostado por aumentar su producción de gas de North Field en julio de 2017 en un 30 por 100, desde los 77 millones de toneladas anuales a los 100 millones hasta 2024. Adicionalmente, quiere complementar la generación eléctrica de ciclo combinado con la producción de energía fotovoltaica, proponiéndose Kahramaa (el operador, distribuidor y transportista energético público) alcanzar los $200 \mathrm{MW}$ en 2020 y los 500 MW a más largo plazo, a través de la construcción de una planta gigante solar operada por la empresa pública Siraj Power. Estos objetivos podrían considerarse un brindis al sol, pues aunque los precios del kW hayan alcanzado mínimos recientemente, siguen sin ser competitivos con la generación basada en el gas, ya que es «gratis» en Qatar. Además, las partículas de polvo del desierto requieren tratamientos especiales para las placas fotovoltaicas, que pueden encarecer los costes unitarios de generación. En definitiva, la imagen verde puede salir muy cara al emirato en un contexto de priorización del gasto público.

\subsection{Del dicho al hecho: la realidad empresarial}

Las necesidades de desarrollo de un país rico y emergente, con un Mundial en cuatro años, son un reclamo para las empresas extranjeras. Sin embargo, tras años de esfuerzos de inversión en infraestructuras, las licitaciones de grandes proyectos públicos y privados llegan a cuentagotas entre 2016 y 2018, con retrasos y con tiempos de adjudicación inciertos, en muchas ocasiones motivados por los problemas de liquidez del mercado.

Los precios bajos y los márgenes estrechos son las variables claves a tener en cuenta para conseguir un proyecto en Qatar en 2018. Para las modificaciones y desviaciones de contrato, las autoridades no son flexibles y los contratos suelen recoger cláusulas duras y penalizaciones que no dudan en ejercer. Más que nunca un análisis de riesgos adecuado es fundamental antes de embarcarse en una operación en Qatar.

Además, la incertidumbre proveniente del bloqueo sobre los suministros y sobre la aprobación de nuevas listas de productos y proveedores, los retrasos detectados en los cobros de empresas y pagos a trabajadores, el elevado coste de vida del trabajador expatriado de cuello blanco y la importancia de presentar una buena oferta financiera complementaria a la $\triangleright$ 
técnica y comercial son términos decisivos en estos momentos.

Esta situación seguramente sea reversible, conforme el Mundial se acerque, confiriendo un poder de negociación a las empresas para poder garantizar la conclusión de sus proyectos a tiempo y con la calidad esperada para un evento de estas características.

De hecho, las condiciones para el negocio continúan mejorando en los últimos meses, según el indicador PMI que elabora IHS para Qatar Financial Centre (4 de julio, QFC). Tras situarse por debajo del umbral de los 50 puntos (que indica un deterioro de las condiciones) entre abril y julio de 2017, el indicador se mantiene al alza en el último dato de junio de 2018 (51,8), aunque ligeramente inferior al del mes de mayo $(52,4)$. Los estímulos de la demanda, la reducción en los precios de venta, el aumento de las nóminas y la mejora en los tiempos de entrega son los aspectos positivos que recoge este indicador.

Existen también unos condicionantes externos a tener en cuenta a la hora de establecerse en el país:

- Políticos, por el aumento del número de licitaciones adjudicadas tras el bloqueo a nacionales de países que han apoyado explícitamente a Qatar.

- Económicos, en beneficio de China, Japón o Corea del Sur, que son los grandes compradores de gas.

- Competitivos, hacia empresas con menor coste de mano de obra en detrimento de la calidad (según el sector y segmento poblacional al que va dirigido).

- Locales, por el que se observa un mayor número de adjudicaciones a empresas qataríes, que, tras adquirir el know-how externo durante años, reclaman ahora su porción del pastel.
Por ello, los últimos grandes proyectos adjudicados han venido de la mano de visitas oficiales de primeras espadas del mundo occidental acompañadas de representación comercial. La diplomacia económica de EEUU, a través del diálogo estratégico con Qatar, las misiones de alto nivel a Gran Bretaña a través de las cámaras de comercio y el Qatar Businessmen Association, las visitas oficiales de los primeros ministros italiano, Angelino Alfano, y francés, Emmanuel Macron, a Doha en agosto y diciembre de 2017, respectivamente, son ejemplos de cómo conseguir réditos económicos en materia militar y civil en Qatar.

\section{4. ¿Qué será de su economía tras el Mundial? El día después}

Los vientos de cola provenientes de un precio de los hidrocarburos al alza y el gasto comprometido para las infraestructuras del Mundial son factores positivos, pero con un límite temporal claro, por lo que la economía debe sostenerse sobre patrones estructurales más duraderos.

Al ser la población una variable endógena al modelo - pues el crecimiento poblacional de los últimos años viene provocado por el aumento en la contratación de expatriados (IMF Art. IV, 2018)_, el gasto en consumo privado está, por tanto, determinado por la coyuntura económica, recuperando los principios de la Ley de Say, por el que la oferta genera su propia demanda. Por ello, la política económica está orientada al estímulo de la oferta, consciente de que el gasto en consumo privado final procedente de la resultante mayor población empleada devuelve el flujo circular de la renta a la economía ${ }^{10}$.

10 No se considera el importe de las remesas de los trabajadores, que alcanzan los 12.300 millones de USD en 2017. 
Es más, los menores salarios y complementos ofrecidos actualmente y la mayor entrada de mano de obra menos cualificada, en detrimento de la cualificada, están reduciendo el gasto doméstico. De hecho, se prevé que las remesas sigan aumentando a largo plazo (abril de 2018, IMF Art. IV) a costa del gasto efectivo real, dado que la mayor parte de los trabajadores menos cualificados envían prácticamente la totalidad de su sueldo a su país para sostener a sus familias (los contratos de los trabajadores de menor cualificación suelen incluir las denominadas allowances, es decir, alojamiento y manutención, por lo que apenas necesitan hacer gastos en Qatar).

Por todo ello, las nuevas condiciones de la oferta en el mercado de bienes, como son los precios competitivos y bajos costes, acarrean un cambio en el perfil del trabajador contratado que termina por comprometer el gasto final que se revierte a la economía.

A más largo plazo, y una vez que el estímulo público procedente del gasto comprometido para el Mundial desaparezca en 2022, el sector privado deberá tomar el relevo como motor del crecimiento económico. La falta de sectores alternativos actuales (aparte del sector de hidrocarburos) que estimulen la economía y aumenten la contratación de mano de obra extranjera, con o sin cualificación, ponen en cuestión el modelo de desarrollo del país.

\section{Conclusión. Una paradoja a la teoría de juegos}

La reacción de Qatar al bloqueo de los países vecinos ha sido contenida y legalista. Qatar no ha dudado en recurrir a las instituciones multilaterales para hacer notar lo que considera una violación de sus derechos y soberanía.
Ante la Organización Mundial del Comercio (OMC) presentó su reclamación por el bloqueo comercial sufrido, solicitando la celebración de consultas en enero de 2018 en el marco del mecanismo de resolución de diferencias de la OMC. Ante la falta de respuesta de los contrarios, se solicitó formalmente un Panel bilateral contra Bahréin, EAU y AS. Las demandas se fundamentan en las restricciones al comercio de bienes y servicios y a la difusión de contenidos de Al Jazeera y derechos de autor. El Cuarteto se acoge a la excepción de las normas de la OMC por motivos de seguridad, argumentados sobre la base del apoyo de Qatar al terrorismo.

Las restricciones sobre el acceso al espacio aéreo de los vecinos también han sido objeto de denuncia ante la Organización Internacional de Transporte Aéreo de Aviación Civil (ICAO en sus siglas en inglés) que no cuenta con mecanismos coercitivos para hacer valer lo firmado por los signatarios. El Cuarteto ha llevado el asunto ante la Corte Internacional de Justicia en La Haya.

Por último, se recurrió ante el Comité de los Derechos Humanos de las Naciones Unidas las separaciones familiares como consecuencia de las prohibiciones de acceso a los países bloqueantes para nacionales qataríes, nuevamente por motivos de seguridad.

El desgaste producido por la fatiga ante el fracaso de las diversas líneas de actuación iniciados con el fin de resolver el conflicto (buenos oficios de Kuwait, llamamientos de Reino Unido, Francia, Alemania, Turquía, Marruecos, etcétera, y aparente presión del presidente Trump) ha llevado a las autoridades qataríes a endurecer su posición, demandando a los EAU ante la Corte Internacional por discriminación, intensificando sus demandas ante los distintos organismos internacionales y prohibiendo la $\triangleright$ 
Agregaduría Comercial de la Oficina Económica y Comercial de la Embajada de España en Qatar

importación de productos de origen en los países del Cuarteto.

Es difícil hacer una previsión sobre la evolución del conflicto a medio y largo plazo. Desde el punto de vista económico, la situación actual carece de sentido. Según la teoría de juegos, el conflicto en Oriente Medio es claramente una situación subóptima en términos de Nash. El equilibrio a corto plazo actual, por el que las partes no llegan a un acuerdo, es inconsistente dinámicamente, pues ambos contendientes tendrían mucho que ganar si ponen fin al bloqueo. Aunque, en cierto modo, no sería ilógico pensar que la paradoja a la teoría de juegos provenga precisamente de un mundo donde el juego de azar está prohibido.

La solución al conflicto, por tanto, vendrá de un planteamiento racional y consistente a largo plazo entre las partes implicadas, siempre que los factores desestabilizantes externos se mantengan neutrales. El compromiso a alcanzar deberá ser generalista, sin entrar al detalle sobre las medidas a emprender, respetando la soberanía nacional y condenando el terrorismo. Ahora mismo, los orgullos prevalecen sobre la racionalidad, pero puede haber un giro inesperado en cualquier momento. ¿Quién sabe? Dios dirá, Inshallah!

\section{Bibliografía}

[1] BLOOMBERG (2018). Exchange rate series Qatar Ryal/ US Dollar.
[2] IMF (2018, May 30). Article IV Consultation, Qatar. Disponible en: https://www.imf.org/en/ News/Articles/2018/05/30/pr18202-qatar2018-article-iv-consultation [Recuperado: 2018, 17 de julio).

[3] IMF (2018, April). WEO database. Disponible en: http://www.imf.org/en/Publications/WEO/ Issues/2018/03/20/world-economic-outlook-april-2018 [Recuperado: 2018, 17 de julio).

[4] OXFORD BUSINESS GROUP (2017). The Report: Qatar 2017.

[5] PRIEGO, A. (2015). «Las primaveras árabes: la influencia de Qatar y sus relaciones con los Estados del Golfo». Revista UNISCI, n.응. 39 .

[6] PRIYADSOUZA COMMUNICATIONS (2017, February $\left.7^{\text {th }}\right)$. Disponible en: http://priyadsouza.com/population-of-qatar-by-nationalityin-2017/

[7] QATAR CENTRAL BANK (2017). $9^{\text {th }}$ Financial Stability Review. Disponible en: http://www. qcb.gov.qa/English/Publications/ReportsAnd Statements/Pages/FinancialStabilityReports. aspx [Recuperado: 2018, 17 de julio].

[8] QATAR CENTRAL BANK (2018). Quarterly Statistical Bulletin.

[9] QATAR FINANCIAL CENTRE (2018, July $4^{\text {th }}$ ). Purchasing Managers' Index (PMI).

[10] QATAR TOURSIM AUTHORITY (2017). Annual Tourism Performance Report. Disponible en: https://www.visitqatar.qa/corporate/statistics/2017 [Recuperado: 2018, el 17 de julio).

[11] QATAR STOCK EXCHANGE, QSE (2018). Disponible en: $h$ ttps://www.qe.com.qa/

[12] UN COMTRADE (2018). Statistics Database. Disponible en: https://comtrade.un.org/ [Recuperado: 2018, el 17 de julio]. 